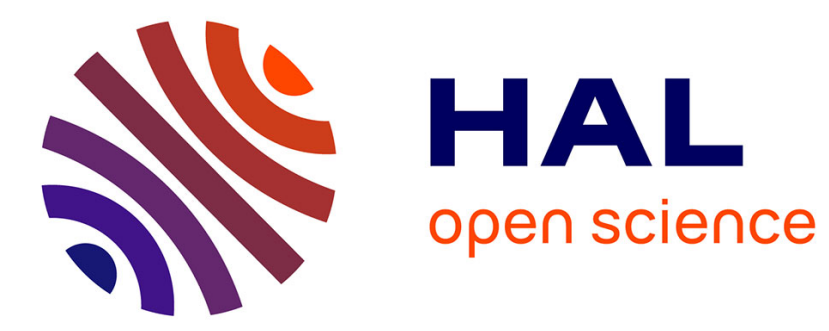

\title{
The Multimodal Dynamics of a Walnut Tree: Experiments and Models
}

M. Rodriguez, S. Ploquin, Bruno B. Moulia, Emmanuel de Langre

\section{To cite this version:}

M. Rodriguez, S. Ploquin, Bruno B. Moulia, Emmanuel de Langre. The Multimodal Dynamics of a Walnut Tree: Experiments and Models. Journal of Applied Mechanics, 2012, 79 (4), pp.044505. 10.1115/1.4005553. hal-00996527

\section{HAL Id: hal-00996527}

https://hal-polytechnique.archives-ouvertes.fr/hal-00996527

Submitted on 28 May 2020

HAL is a multi-disciplinary open access archive for the deposit and dissemination of scientific research documents, whether they are published or not. The documents may come from teaching and research institutions in France or abroad, or from public or private research centers.
L'archive ouverte pluridisciplinaire HAL, est destinée au dépôt et à la diffusion de documents scientifiques de niveau recherche, publiés ou non, émanant des établissements d'enseignement et de recherche français ou étrangers, des laboratoires publics ou privés. 


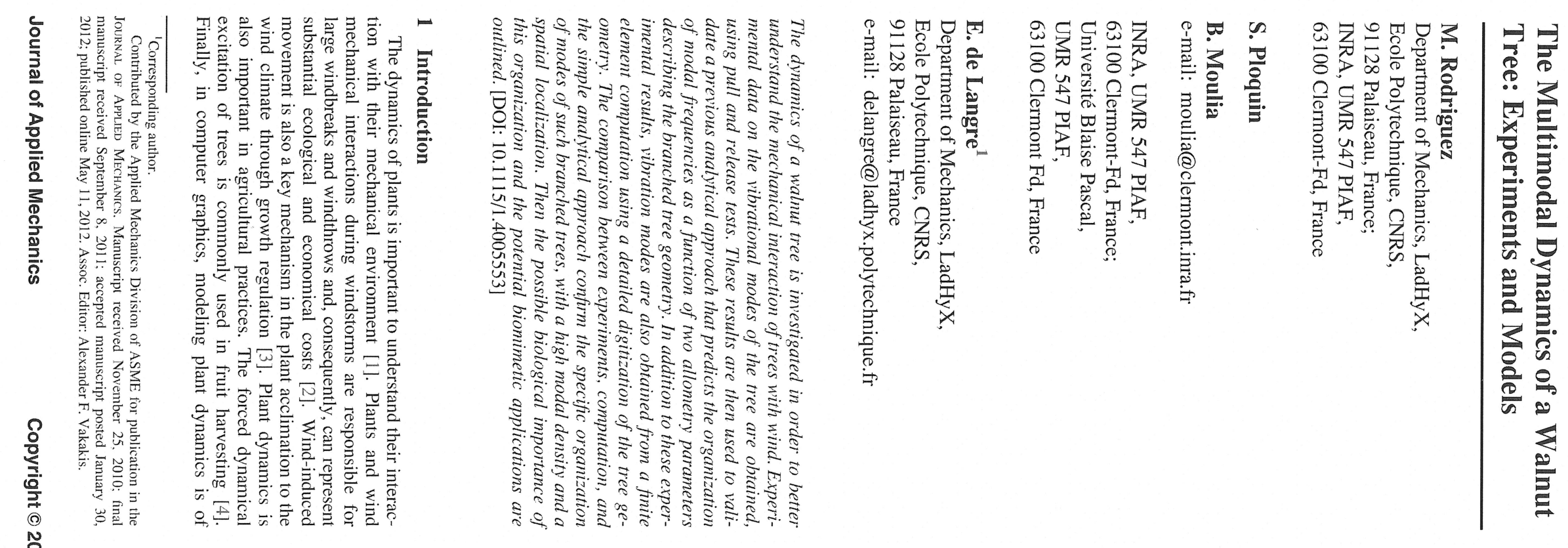

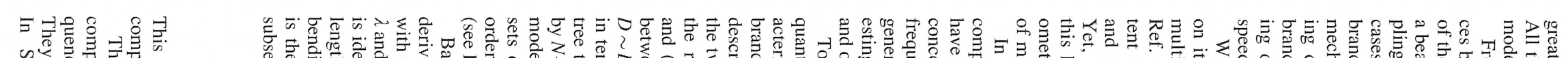

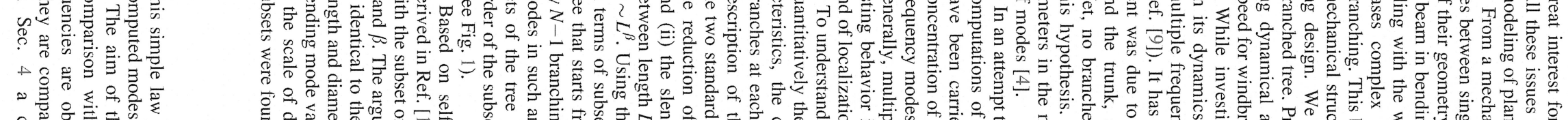

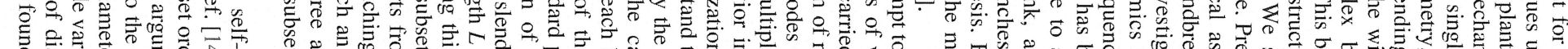

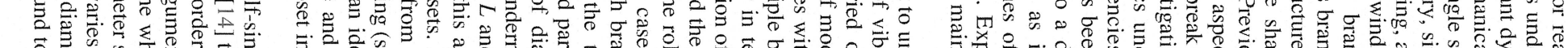

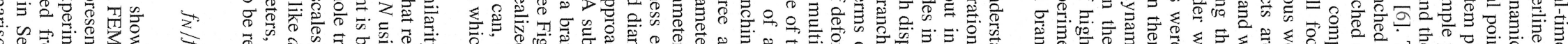

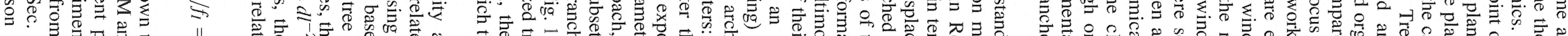

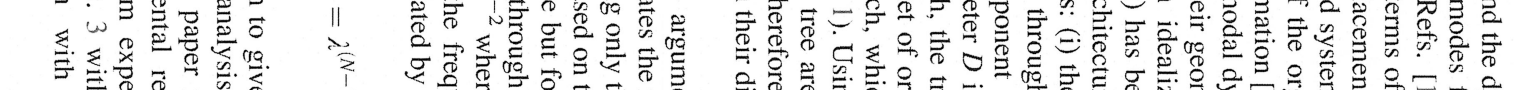
$\begin{array}{lll} & \\ 0 & \end{array}$

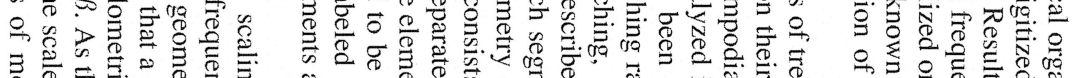

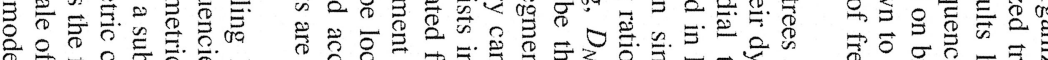

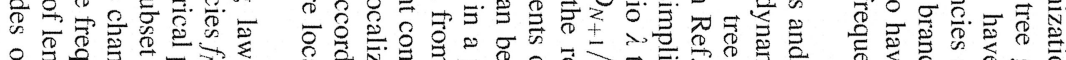

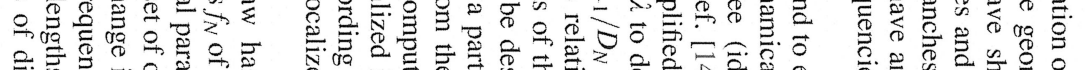

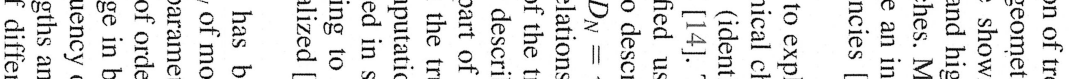

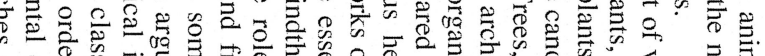

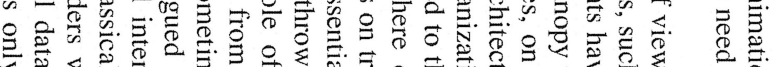

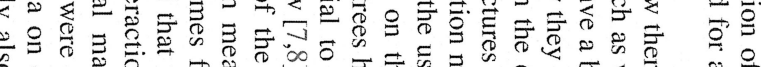

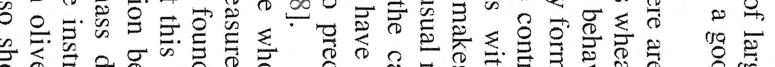

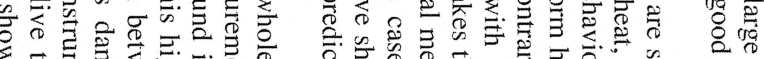

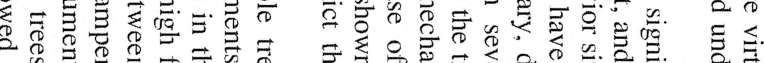

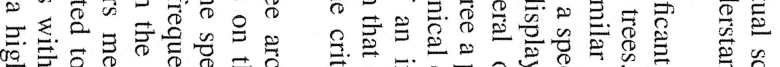

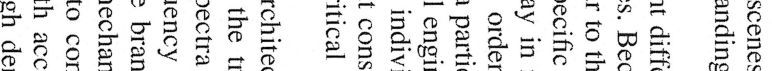

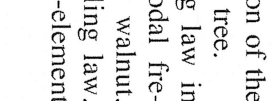



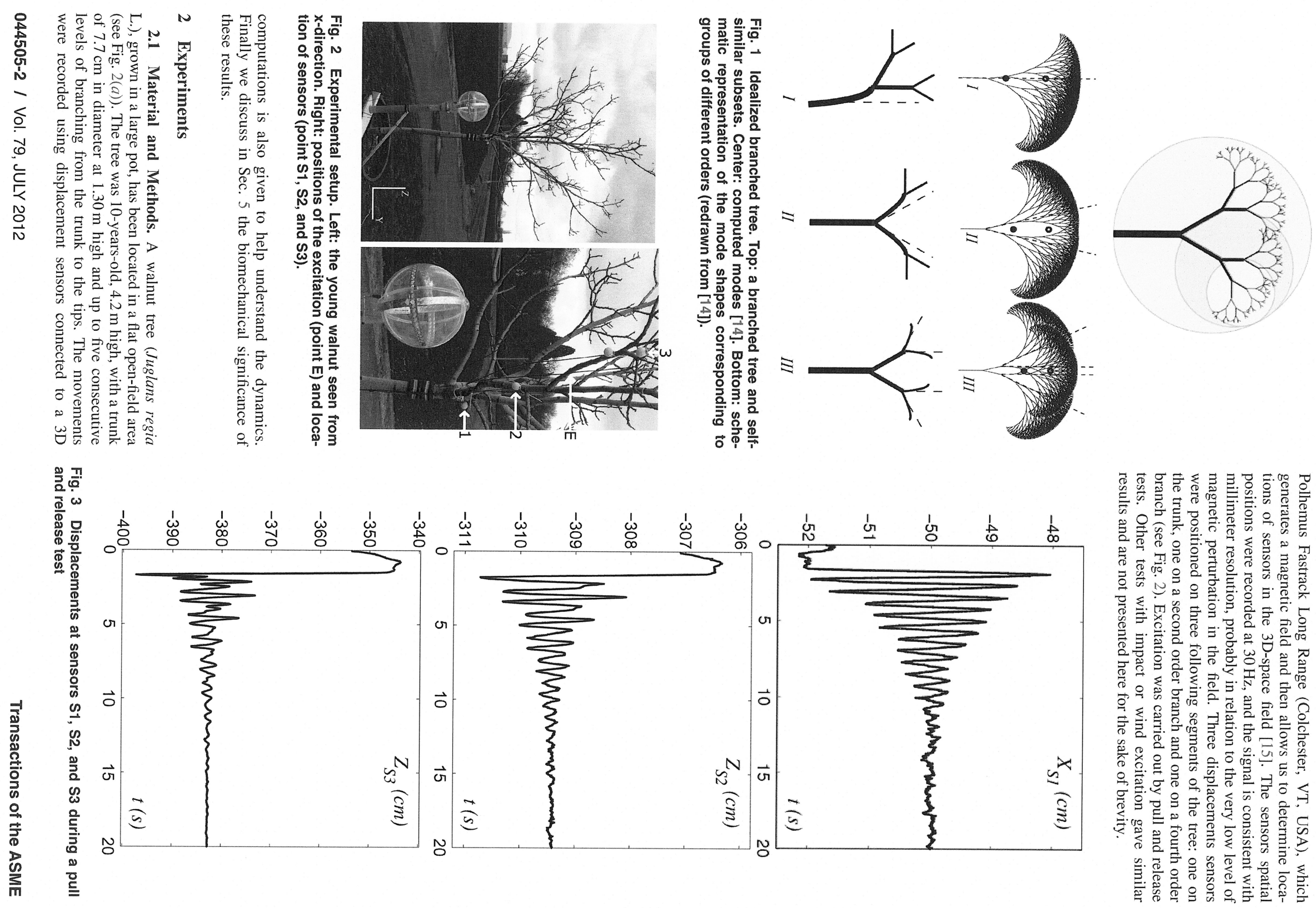

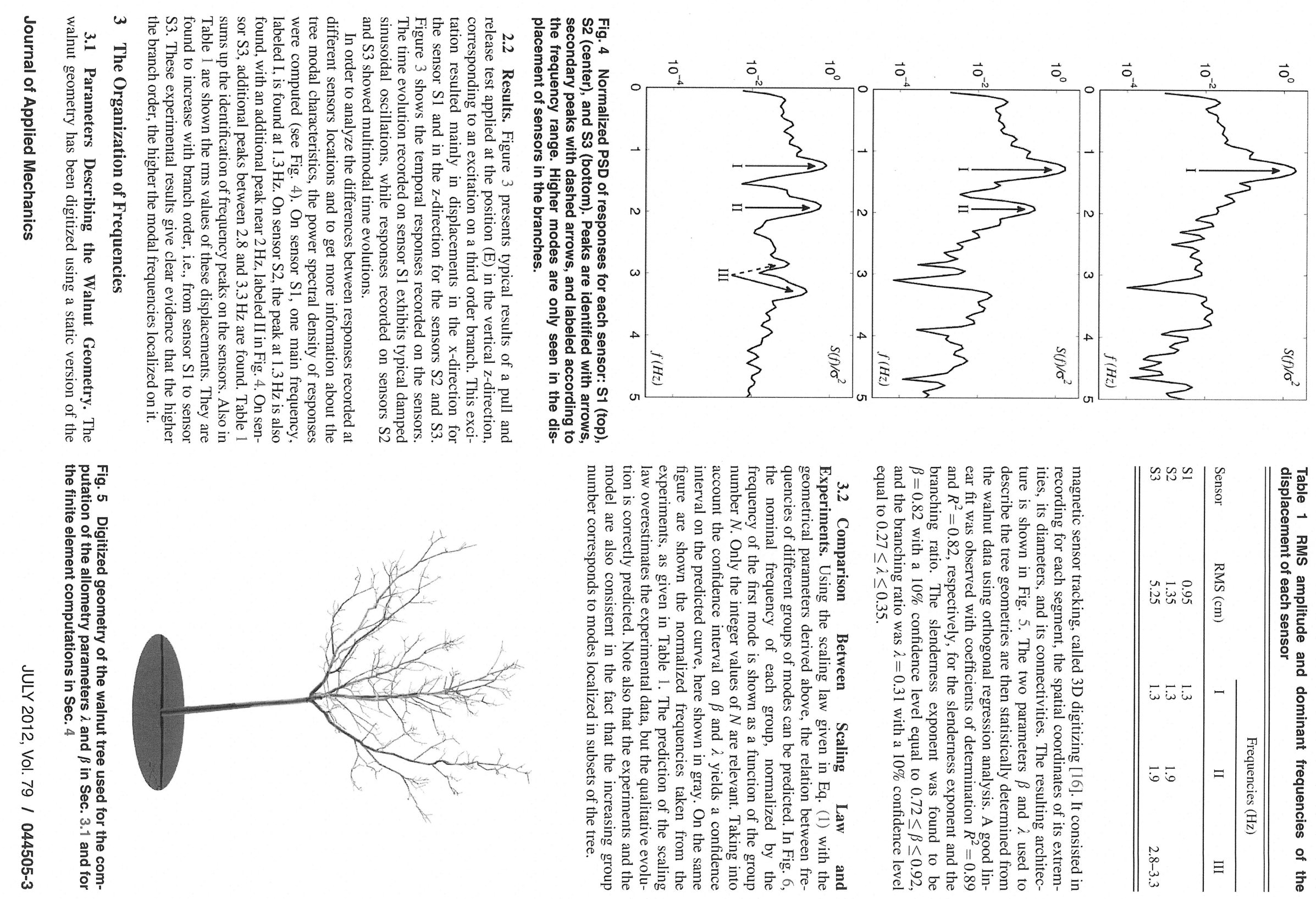

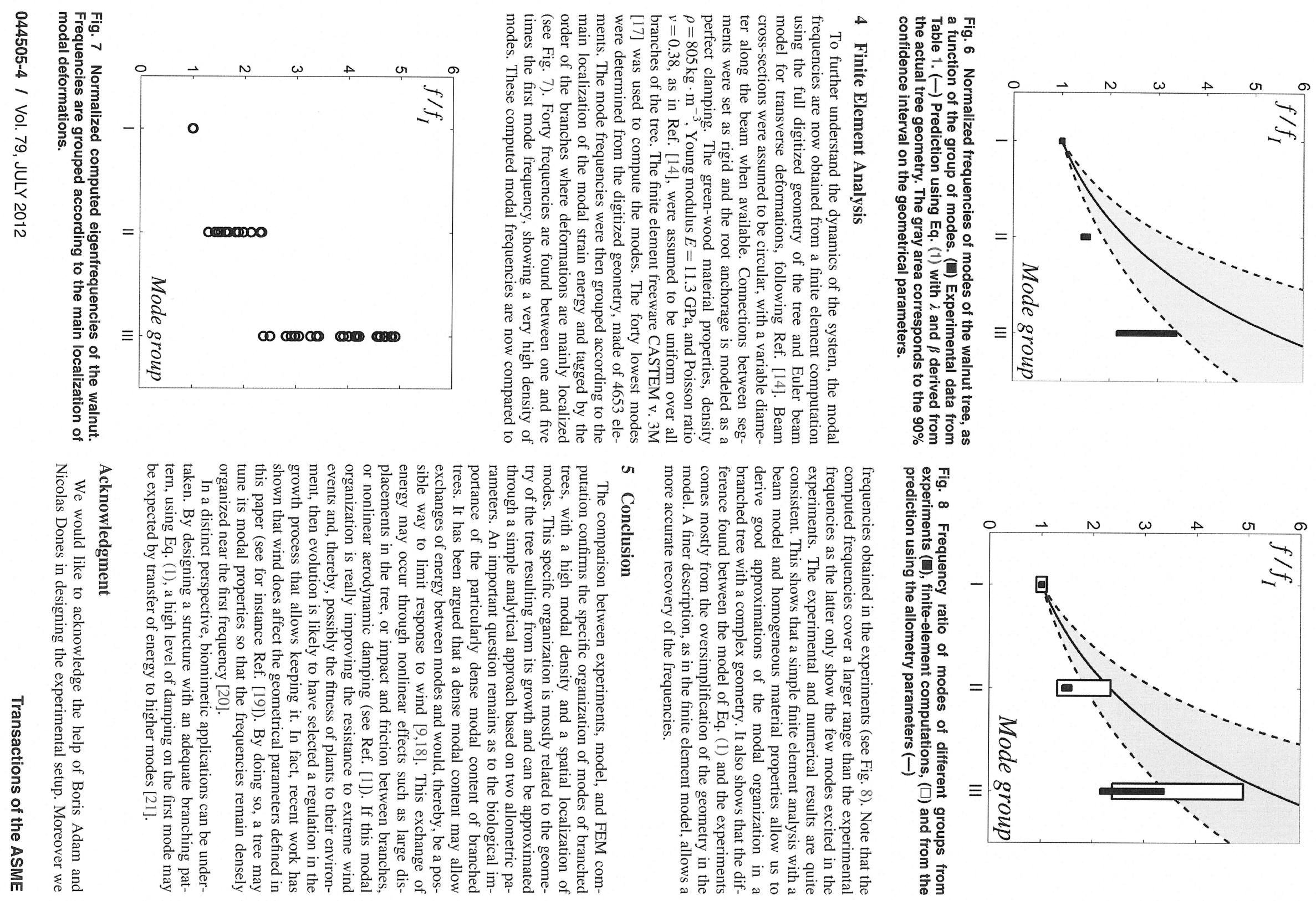

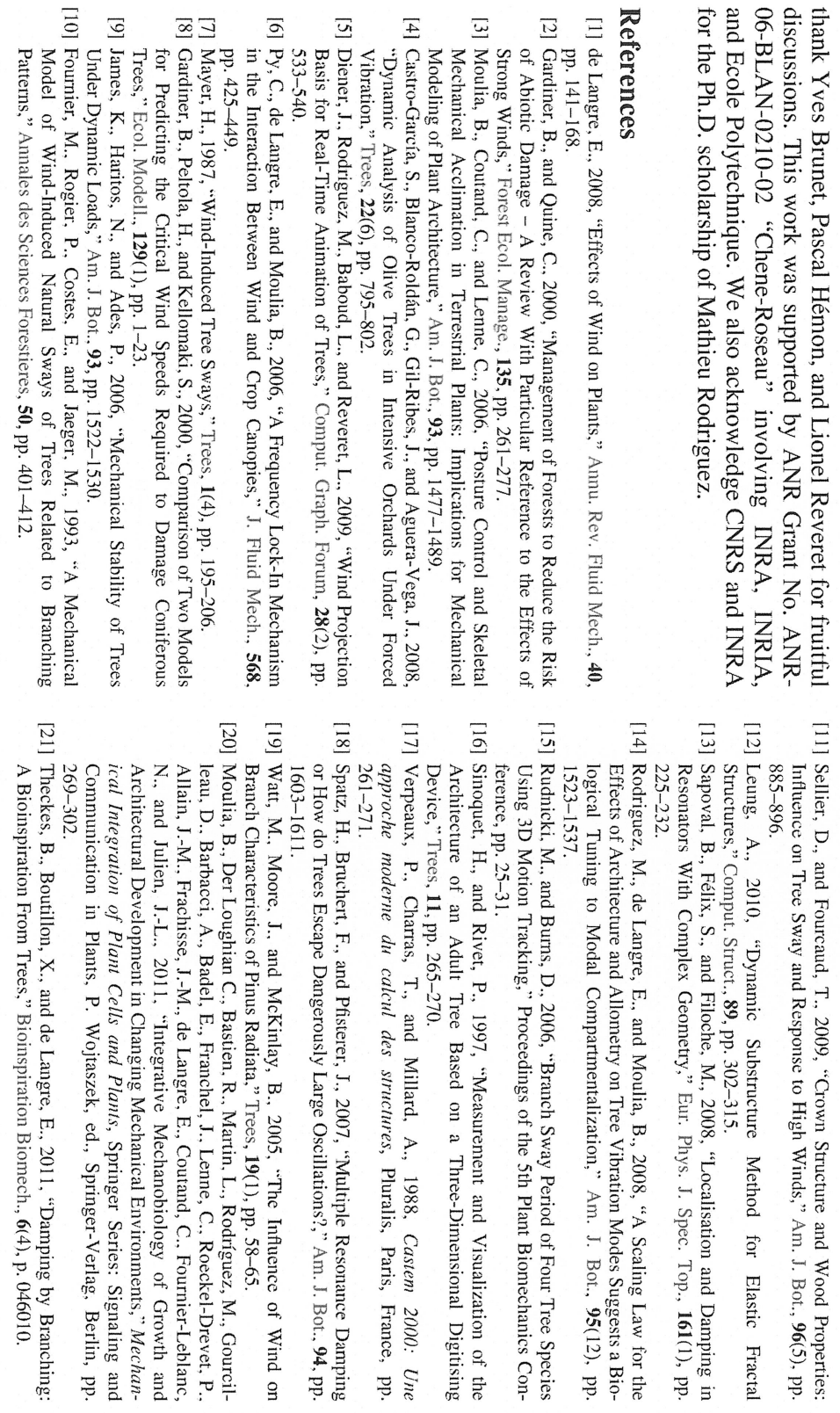